\title{
Brazilian journals in electronic format: from diskettes to Open Access
}

The first scientific communication revolution took place in the XVII century following Gutenberg's invention of the press, with the publication of scientific journals in Europe in 1665. For more than 300 years, journal publishing has not essentially changed, even in the developed world. Intrinsic characteristics of scientific journals remain almost the same since they were first defined: a series of selected articles, reviewed by peers, published in regular periods of time, under a given title and the supervision of an Editorial Board. Traditional flow of scientific information resulted in expensive printed versions, with limited distribution and sometimes unaffordable subscriptions.

Another scientific communication revolution began in the early 90's, when computer development caused a tremendous transformation in journal publishing all over the world. Journals moved from paper to electronic format. Leaving behind the traditional model, science editors started publishing electronically, favoring wider distribution and reducing costs. Electronic journals are better known to be published on the Internet, but the first electronic journals started with the simplest electronic format: diskettes and, later, CD-ROMs.

This was the case of the first electronic scholarly journal in Brazil, created 12 years ago The Journal of Venomous Animals and Toxins, which had its title changed in 2002 to The Journal of Venomous Animals and Toxins including Tropical Diseases. The Journal was first published in 1995 on a 3.5" diskette, inserted in the internal portion of a paper hardcover.

I think it is not difficult to imagine what a difference this journal made when arrived at libraries. I still remember when its first issue arrived at BIREME! Immediately, we had to discuss how to shelve it in the traditional library stacks, how to circulate it, how users could read it at the library reading room, and so on. As stated in the first issue, "A 386 IBM-PC or IBM-compatible computer with software Windows 3.1 or greater must be used for reading and printing". We were facing a new paradigm in publishing that led us to rethink our traditional journal processing flow and access to journal collection at the library.

From diskette format, The Journal of Venomous Animals and Toxins evolved in 1996 to its own website (www.jvat.org.br) and in the next year it was accepted in SciELO Scientific Electronic Library Online collection (www.scielo.br). In the meantime, it was also published on CD-ROM.

Electronic journals have changed users and libraries modus operandi and librarians' culture on dealing with access to information. Computer stations and later internet connections were made available to users in libraries to enable access to these journals. 
R. C. F. Castro. BRAZILIAN JOURNALS IN ELECTRONIC FORMAT: FROM DISKETTES TO OPEN ACCESS. J. Venom. Anim. Toxins incl. Trop. Dis., 2006, 12, 1, p. 2

On the other hand, users had to get accustomed to reading in computer screens and editors started rethinking distribution, financing and subscriptions.

Discussions on new funding models and equity in access and use of scientific information were the basis for the organization in 2001 of a meeting in Budapest to discuss open access to scientific and scholarly literature. The international movement towards Open Access began with the Budapest Open Access Initiative (BOAl), which first defined open access journals as "those that are freely available on the Internet, permitting any users to read, download, copy, distribute, print, search, or link to the full texts of these articles, but giving authors control over the integrity of their work and the right to be properly acknowledged and cited".

All SciELO journals, such as The Journal of Venomous Animals and Toxins including Tropical Diseases, are open access journals. According to the Directory of Open Access Journals (http://www.doaj.org/) more than 2,000 Open Access journals are being currently published, of which more than 500 are available at article level, including SciELO journals. Discussions on Open Access for Developing Countries were initiated by BIREME in 2005, resulting in the Salvador Declaration on Open Access: the Developing World Perspective, available at http://www.icml9.org/meetings/openaccess/public/documents/declaration.htm.

It is clear that electronic publishing in Brazil is following international developments and trends: at the time electronic publishing was still beginning in other regions, a Brazilian journal was being published electronically and many years before the Open Access movement has started, BIREME and Fapesp had launched SciELO, the first Open Access initiative in the developing world. Open Access improves visibility, accessibility and use of scientific journals, and it has been proved that SciELO journals are being more widely known and cited.

Regina Célia Figueiredo Castro BIREME/OPAS/OMS castrore@bireme.ops-oms.org 